Placide, of St. Amour, and Crispinien, of Toulon, and by the two Brothers Bonaventura and Gregory, all of the Order of St. Francis. Father Gregory, it is said, was the celebrated Lyonnaise geograner, Henry Marchand. In speaking of these discoveries at the Paris Geographical Society, M. R. Cortambert showed that there was nothing extraordinary in them. From the fifteenth century most of the maps make the Congo issue from a great mass of water in the interior of the African continent. No doubt all the information in these old maps was furnished by the Portuguese. M. Vivien de St. Martin is also of this opinion. The Portuguese traders were quite au courant with the geography of the interior of Africa, and all the maps, even that of Fra. Mauro ( $5^{\text {th }}$ century) represent the Nile issuing from lakes to the south of the equator, and give an idea of the course of the Congo, similar to that made known by Stanley. M. St. Martin reminded the Society, moreover, that Ptolemy himself had indicated three immense lakes in the centre of Africa from which issued the Nile and the Congo; only in his map these lakes are placed much too far south. Father Kircher, in his " Mundus Subterraneus," published at Amsterdam in I653, gives a map showing four large lakes, from one of which, called Zaire, both the Nile and the Congo are made to issue. Kircher states that he obtained his information from the General Procurator of the Jesuits for these provinces, who lent him a manuscript of Father Païs. This manuscript may possibly be still preserved in the Jesuit College at Rome.

Paris Geographical Society.-Besides the medals to Mr. Stanley and M. St. Martin, the Paris Geographical Society will give medals to Dr. Harmand for his exploration of the Mekong and the coast of Anam, and to M. Ujfalvy for his travels in Turkestan. The Bulletin for December contains an important geographical and statistical article on Kashgar, compiled from various sources by M. J B Paquier, an itinerary on the Yang-tsze from Shung-shing to Yun-nan-fu, by $M$. Rocher, and a valuable summary of the geodetic work of the Russian Geographical Society in Asia, by Col. Chanoine.

NOTE ON THE DISCOVERY OF THE LIQUE. FACTION OF AIR AND OF THE SO-CALLED PERMANENT GASES

$\mathbb{N}$ the Notes on "Recent Science," in this month's Nineteenth Century, the writer, in an account of the results of the researches of M. Pictet and M. Cailletet on the condensation of the so-called permanent gases, draws attention to the long-neglected paper of Mr. Perkins "On the Compressibility of Water, Air, and other Fluids," an abstract of whicb, and apparently the only one with which the writer is acquainted, appeared in Thomson's Annals of Philosophy, N. S., vol. vi., 1823. The paper was intended for the Royal Society, but; being mislaid, was not read at the appointed time. Either it or a second paper was, however, brought before the society on June 15, 1826, and appears in the Philosophical Transactions for that year. In this paper, as in the brief record in the Annals, Mr. Perkins announces that he had effected the liquefaction of aimospheric air, and other gases, by a pressure of upwards of $x, 000$ atmospheres, and fully describes the apparatus which he had employed, which is, in principle, very similar to that of $M$. Cailletet. He thus describes his results in the case of aëriform fluids :-

"In the course of my experiments on the compression of atmospheric air by the same apparatus which had been used for compressing water, I observed a curious fact which induced me to extend the experiment, viz., that of the air beginning to disappear at a pressure of 500 atmospheres, evidently by partial liquefaction, which is indicated by the quicksilver not settling down to a level with its surface. At an increased pressure of 600 atmospheres, the quicksilver was suspended about $\frac{1}{8}$ th of the volume up the tube or gasometer; at 800 atmospheres it remained about $\frac{1}{3}$ up the tube ; at 1,000 atmospheres, $\frac{2}{3}$ up the tube ; and small globules of liquid began to form about the top of it; at $r, 200$ atmospheres the quicksilver remained $\frac{3}{4}$ up the tube, and a beautiful transparent liquid was seen on the surface of the quicksilver, in quantity about $\frac{3}{2000}$ part of the column of air. On another occasion a second tube was charged with 'carburetted hydrogen' and subjected to pressure; it began to liquefy at about 40 atmospheres, and at 1,200 atmospheres the whole was liquefied."

Mr. Perkins goes on to say: "These instances of apparent condensation of gaseous fluids were first observed in January, 1822 , but for want of chemical knowledge requisite to ascertain the exact nature of the liquids produced, I did not pursue the inquiry further; and as the subject has been taken up by those who are eminently qualified for the investigation, I need not regret my inability to make full advantage of the power. I had the means of applying."

Mr. Perkins's observations seem to have attracted little attention at the time they were published, and have since been, apparently, almost forgotten. Although they do not in the least detract from the great merit of $\mathrm{M}$. Cailletet's work, they undoubtedly have their place in the history of this subject of the liquefaction of the gases.

It may be worth while to point out that the statement that all the gases known to the chemist have now been liquefied is not strictly true. The most recently-discovered of these-phosphorus pentafluoride-has not yet been seen in the liquid state, although there is not the least reason for believing that it will constitute an excep. tion to the general law,

T. E. THORPE

\section{HELMHOLTZ'S VOWEL THEORY AND THE PHONOGRAPH}

THE following experiments with the phonograph are of interest as throwing light on the nature of vowel sounds :-

Let a set of vowel sounds, as A, E, I, O, U (pronounced in Italian fashion) be spoken to the phonograph in any pitch, and with the barrel of the instrument turned at a definite rate. Then let the phonograph be made to speak them, first at the same rate, and then at a much higher or lower speed. The pitch is, of course, altered, but the vowel sounds retain their quality when the barrel of the phonograph is turned at very different rates. We have made this experiment at speeds varying from about three to one, and we can detect no alteration in the quality of the sounds.

According to Helmholtz, the characteristic quality of each vowel is given by the prominence of a constituent note or notes, of definite or approximately definite absolute pitch, in the sounds uttered. Now obviously, the absolute pitches of the constituents of the vowel-sounds in the above experiment were all altered in the same proportion, so that the absolute pitch of the prominent notes varied greatly; but yet the vowel quality was unchanged. This experiment, therefore, appears to give results in contradiction of Helmboltz's theory as we understand it.

At the same time we have found, in the course of experiments, of which a full account will shortly be communicated to the Royal Society of Edinburgh, that if a scale be sung to the phonograph with one vowel sound, such as $O$, the wave-form of the marks on the tinfoil does not remain unchanged at all pitches. We have not yet had time to analyse the curves so obtained into their harmonic constituents. Such an analysis will show whether the changes we have observed in the wave-form as the pitch rises, are due to a change in the relation of the amplitudes of the constituents present, or only to a variation of phase.

Edinburgh, March II
FIE.MING JENKIN J. A. EWING 